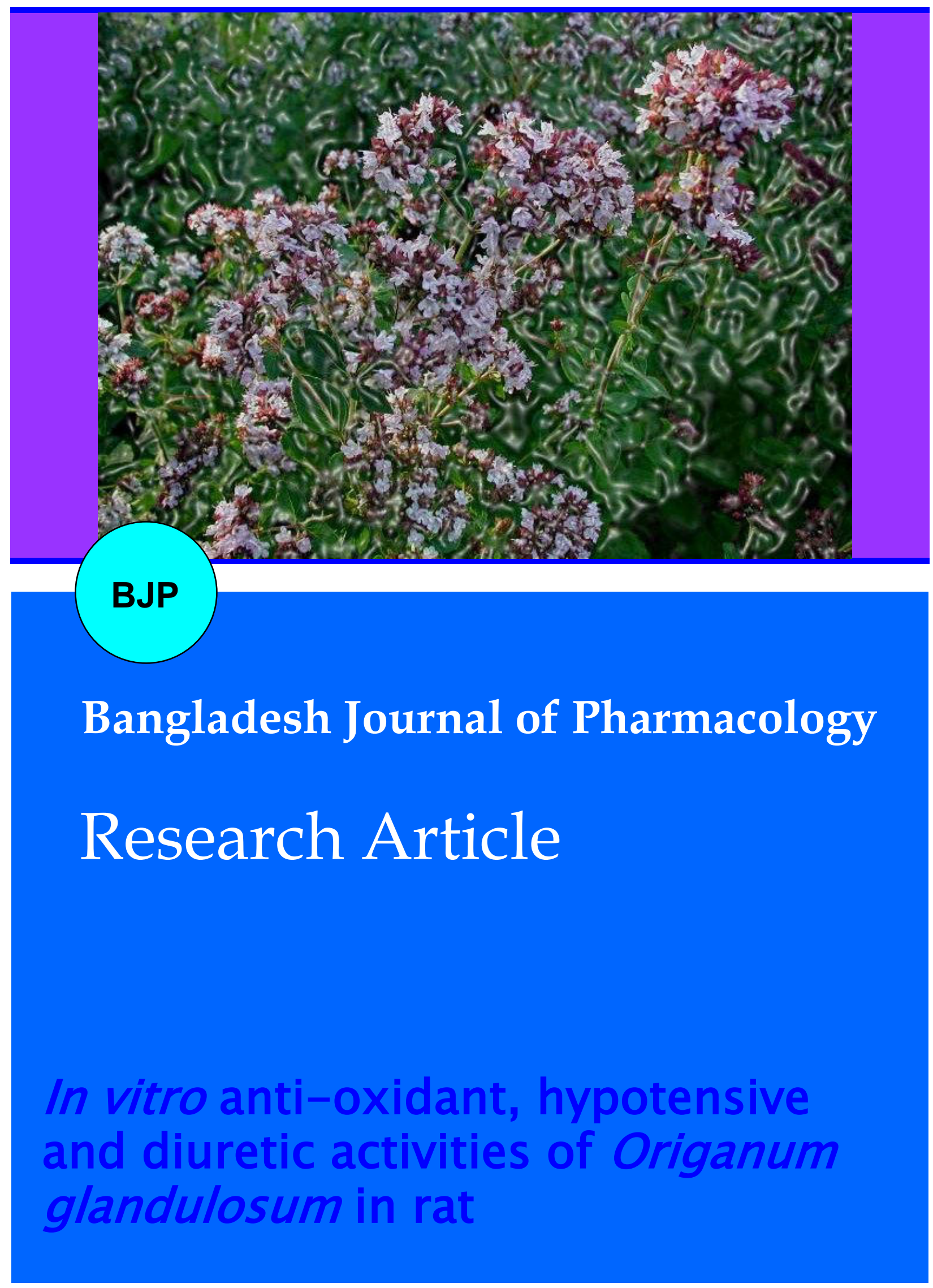


Abstracted/indexed in Academic Search Complete, Agroforestry Abstracts, Asia Journals Online, Bangladesh Journals Online, Biological Abstracts, BIOSIS Previews, CAB Abstracts, Current Abstracts, Directory of Open Access Journals, EMBASE/Excerpta Medica, Global Health, Google Scholar, HINARI (WHO), International Pharmaceutical Abstracts, Open J-gate, Science Citation Index Expanded, SCOPUS and Social Sciences Citation Index

\title{
In vitro anti-oxidant, hypotensive and diuretic activities of Origanum glandulosum in rat
}

\author{
Amel Bouazizi ${ }^{1}$, Seddik Khennouf ${ }^{1}$, Musa Abu Zarga² and Shtaywy Abdalla3
}

${ }^{1}$ Laboratory of Phytotherapy Applied to Chronic Diseases, Department of Biology and Animal Physiology, Faculty of Nature and Life Sciences, University Ferhat Abbas, Setif 1, 19000, Algeria; 'Natural Products Laboratory, Department of Chemistry, Faculty of Science, The University of Jordan, Amman, Jordan; ${ }^{3}$ Animal and Human Physiology Laboratory, Department of Biology, Faculty of Science, The University of Jordan, Amman, Jordan.

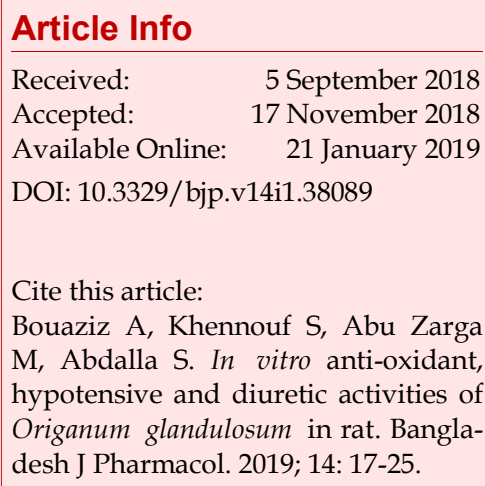

\begin{abstract}
The objective of this study was to evaluate the in vitro anti-oxidant, hypotensive and the diuretic activities of Origanum glandulosum leaves in rat. Chemical analysis revealed the isolation of katuranin and 5-isopropyl-3methylphenol. Ethyl acetate extract possessed highest scavenging activity against DPPH and hydroxyl radicals. Intravenous administration of extracts (0.04 to $12 \mathrm{mg} / \mathrm{kg}$ body weight) dose-dependently decreased the blood pressure (systolic, diastolic and mean) of the anesthetized rat. Methanol extract showed dose-dependent diuretic activity by increasing the urine output $(77 \%)$ and the urinary excretion of sodium and potassium. In conclusion, this study supports the use of O. glansulosum in traditional medicine as hypotensive and diuretic agents.
\end{abstract}

\section{Introduction}

Oxidative stress is an imbalance between the cellular generation of ROS and the capacity of anti-oxidants in favor of oxidants (Wu et al., 2015) that can be an important mediator in damaging cell structures, including lipids and membranes, proteins, and DNA. Currently, this oxidative stress has been implicated in the pathogenesis of various diseases including hypertension, hypercholesterolemia, diabetes, heart failure, inflammation and aging (Gönenç et al., 2013).

Hypertension is one of the important risk factors for the cardiovascular diseases and is associated mostly with coronary heart disease, renal disease and cerebrovascular disease. Therefore, it is a major cause of morbidity and mortality (Athiroh et al., 2014). The recent studies have predicted that the prevalence of hypertension, at global level, will increase from 1 billion of the adults to 1.5 billion in the year 2025 (Gutiérreza et al., 2014).

Plant phenolics and flavonoids represent the major groups of plant constituents that work predominantly as powerful anti-oxidants or scavenger of free radicals. They play beneficial role in human health and cure/ prevent many diseases such as cardiovascular diseases, hypertension, inflammatory disorders, cancer, and diabetes which occur due to the deregulation of free radicals generation in the cells (Chouhan and Singh, 2011).

Thus, much attention has been paid to the study of medicinal plants, including the screening of natural bioactive compounds such as phenolic compounds with the ability to cure, prevent the progression of many diseases (Yadegarinia et al., 2006) and the exploration of traditional medicines may reveal new treatment options to increase the therapeutic arsenal by the discovery of novel medicines and to offer lower cost alternatives in developing countries that increasingly 
share the same concerns (Qu et al., 2016).

Origanum glandulosum Desf. is an endemic spontaneous plant of Algeria and Tunisia. In Algeria, this species is called "Zaatar" (Oukil et al., 2011) and it is used for the treatment of cough, bronchitis, common cold, fever (Khadir et al., 2013), hypertension and digestive disorders (Boudjelal et al., 2013). However, different studies have been published on its pharmacological properties as antibacterial, antifungal (Oukil et al., 2011; Khadir et al., 2013) and anti-oxidant activities (Oukil et al., 2011; Belhattab et al., 2005). But, no previous pharmacological or clinical study was carried out to test the hypotensive and diuretic effects of this plant. Thus, the objectives of our study were to evaluate the hypotensive and diuretic activities of O. glandulosum in healthy albino rats. Also, the phytochemical analysis and the in vitro anti-oxidant properties of various extracts from this plant were investigated.

\section{Materials and Methods}

\section{Plant material}

The leaves of $O$. glandulosum were collected from the Setif region in Northeastern of Algeria during June 2012. The plant was identified by Prof. Hocine Laouar, Institute of Agronomy, Setif (Algeria) and a voucher specimen (No.: LO 215) was deposited in the Nature and Life Sciences Faculty herbarium (University Ferhat, Abbas, Setif 1, Algeria). The leaves were shadow-dried and powdered using an electrical grinder.

\section{Animals}

Healthy male adult albino rats, weighing 200-250 g were used. Animals were housed in an air-conditioned animal room (12 hours light/dark cycle, $\left.23 \pm 2{ }^{\circ} \mathrm{C}\right)$. All the animals were given food and water ad libitum.

\section{Phytochemical analysis of phenolic compounds}

Phenolic compounds were extracted from the powder according to Markham (1982) with slight modification. One kilogram of the plant powder was extracted with 5L methanol $(85 \%)$ at room temperature for five days. The filtered solvent was evaporated under reduced pressure in a rotary evaporator at $40{ }^{\circ} \mathrm{C}$ and lyophilized to afford a crude methanol extract (100.2 g). The methanol extract $(100 \mathrm{~g})$ was dissolved in 1L watermethanol mixture (9:1) and was then partitioned by successive extractions with different solvents of increasing polarity (hexane, chloroform and ethyl acetate). Each fraction was evaporated to dryness under reduced pressure to obtain hexane, chloroform, ethyl acetate extracts, and the remaining aqueous extracts. After that, $15 \mathrm{~g}$ of ethyl acetate was dissolved in methanol and adsorbed on $15 \mathrm{~g}$ of silica gel (Kieselgel $\left.60 \mathrm{HF}_{254}\right)$ and then loaded on a silica gel column (0.063$0.2 \mathrm{~mm}$, Riedel-Dehaen, $2.8 \mathrm{~cm}$ i.d.) packed in chloro- form. The column was first eluted with chloroform, and then with chloroform-methanol mixture of increasing polarity. Totally, 38 fractions ( $250 \mathrm{~mL}$ for each) were obtained and similar fractions were combined according to their thin layer chromatographic plates, using different solvent systems. The structures of the isolated compounds were determined by NMR and mass spectrometry. ${ }^{13} \mathrm{C}-\mathrm{NMR},{ }^{1} \mathrm{H}-\mathrm{NMR}, \mathrm{DEPT}-\mathrm{NMR}$ and $2 \mathrm{D}-$ NMR (HMQC, COSY 45 and HMBC) spectra were recorded using a Brucker $500 \mathrm{MHz}$ spectrometer. Electrospray ionisation mass spectra were recorded using Brucker Daltonics Apex IV, 7.0 T Ultra shield Plus. Chemical shifts were presented as part per million (ppm) or the $\delta$-scale relative to tetramethylsilane (TMS).

\section{Determination of total polyphenols content}

Total phenolic contents were estimated by FolinCiocalteu method (Li et al., 2007). Such method consists of Folin-ciocalteu's reagent reduction by the phenolic hydroxyl groups, resulting in the formation of a blue product in alkaline solution. Briefly, $100 \mu \mathrm{L}$ of plant extracts were added to $500 \mu \mathrm{L}$ of Folin-Ciocalteu reagent (diluted 10 times). After $4 \mathrm{~min}, 400 \mu \mathrm{L}$ of sodium carbonate solution $(7.5 \%)$ was added. Subsequently, the shaken mixture was allowed to stand for 90 min at room temperature, and then the absorbance of all samples was measured at $760 \mathrm{~nm}$. The amount of total polyphenols in different extracts was determined from a standard calibration curve of gallic acid ( 0.00 to $160 \mu \mathrm{g} / \mathrm{mL}$ ) and the results were expressed in $\mathrm{mg}$ $\mathrm{GAE} / \mathrm{g}$ of extract.

\section{Determination of total flavonoids content}

Total flavonoids content was estimated according to aluminum chloride method (Bahorun et al., 1996). Aliquot of $1 \mathrm{~mL}$ of each extract was added to equal volume of a solution of $2 \%$ aluminum chloride. The mixture was vigorously shaken, and the absorbance was read at $430 \mathrm{~nm}$ versus methanol blank after incubation in dark at room temperature for $10 \mathrm{~min}$. Quercetin (0-40 $\mu \mathrm{g} / \mathrm{mL})$ was used as standard for the calibration curve and flavonoids contents were expressed as $\mu \mathrm{g}$ quercetin equivalent (QE)/ mg of dry extract.

\section{Anti-oxidant activity of plant extracts \\ DPPH radical scavenging assay}

Free radical-scavenging activity of the plant extracts of O. glandulosum was measured in terms of the hydrogen donating or radical-scavenging ability using the stable radical DPPH (2,2'-diphenyl-1-picrylhydrazyl) according to published procedure of Burits and Bucar (2000) with slight modification. Briefly, $50 \mu \mathrm{L}$ of various extract dilutions were mixed with $5 \mathrm{~mL}$ of $0.004 \%$ methanol solution of DPPH. After an incubation period of $30 \mathrm{~min}$ in dark at room temperature, the absorbance was measured at $517 \mathrm{~nm}$. BHT was used as standard. 
Inhibition of free radical DPPH in percent (I\%) was calculated using the following equation:

$\mathrm{I} \%=100\left(\mathrm{~A}_{\text {control }}-\mathrm{A}_{\text {sample }}\right) / \mathrm{A}_{\text {control }}$

where $\mathrm{A}_{\text {control }}$ was the absorbance of blank solution (containing all reagents except the test compound), and $\mathrm{A}_{\text {sample was the }}$ absorbance in the presence of extract

The extract concentration that produces $50 \%$ inhibition $\left(\mathrm{IC}_{50}\right)$ was calculated from the plot of inhibition percentage against extract concentration. A lower $\mathrm{IC}_{50}$ value corresponds to a higher anti-oxidant activity of the extract.

\section{Hydroxyl radical scavenging assay}

The hydroxyl radical scavenging activity of $O$. glandulosum extracts was carried out as described by $\mathrm{Li}$ et al. (2008) with slight modifications. Briefly, a mixture of $100 \mu \mathrm{L}$ of 1,10 -phenanthroline $(5 \mathrm{mM}), 100 \mu \mathrm{L}$ of $\mathrm{FeSO}_{4}(5 \mathrm{mM})$ and $100 \mu \mathrm{L}$ of EDTA $(15 \mathrm{mM}), 70 \mu \mathrm{L}$ of sodium phosphate buffer $(0.2 \mathrm{M}, \mathrm{pH} 7.4)$ were added to $100 \mu \mathrm{L}$ of extract solution and $140 \mu \mathrm{L}$ of hydrogen peroxide $(0.01 \%)$. After 1 hour of incubation at $37^{\circ} \mathrm{C}$ in water bath, the absorbance was read at $536 \mathrm{~nm}$. Vitamin $\mathrm{C}$ was used as a positive control. The scavenging activity of hydroxyl radical effect was calculated according to the following equation:

Hydroxyl radical scavenging activity $(\%)=\left(\right.$ As $\left.-\mathrm{A}_{0}\right) \times$ $100 /\left(\mathrm{A}_{\mathrm{c}}-\mathrm{A}_{0}\right)$

Where, As was the absorbance of the sample (in the presence of the extract), $\mathrm{A}_{0}$ was the absorbance of the blank (distilled water); and $A_{c}$ was the absorbance of a control in the absence of hydrogen peroxide

\section{Box 1: Blood Pressure Measurement in rat}

\section{Principle}

Blood pressure can be measured in anesthetized rats by simply connecting a catheter to a pressure transducer. Carotid artery contains baroreceptors for evaluation of blood pressure and femoral artery for the injection of extact only. Femoral artery is commonly used.

\section{Requirements}

Cannula; Gilson polygraph; Extract (methanol and ethyl acetate); Rat; Sodium thiopental; P23AA Statham pressure transducer; Syringe

\section{Procedure}

Step 1: The rat was anesthetized with an intraperitoneal injection of sodium thiopental $(50 \mathrm{mg} / \mathrm{kg})$

Step 2: The trachea was exposed and cannulated to facilitate easy respiration

Step 3: The right carotid artery was cannulated and connected to P23AA Statham pressure transducer situated at the level of the heart and connected to a Gilson polygraph

\section{Evaluation of the diuretic activity}

The diuretic activity was determined following the methods used by Zhang et al. (2010) with slight modification. The rats were randomly distributed into five groups of five rats each with similar average body weight and then were fasted and deprived of food for 18 hours with free access to water. Before treatment, the animals were pretreated with physiological saline $(0.9 \%$ $\mathrm{NaCl}$ ) at an oral dose of $25 \mathrm{~mL} / \mathrm{kg}$, to impose a uniform water and salt load. Each group was then treated as described in grouping and dosing section orally by gavage. Group 1 served as neutral control, received saline ( $5 \mathrm{~mL} / \mathrm{kg})$; Group 2 served as positive control, received furosemide $(20 \mathrm{mg} / \mathrm{kg}) ;$ Groups 3,4 and 5 received 100, 300 and $600 \mathrm{mg} / \mathrm{kg}$ body weight of methanol extract, respectively.

Immediately after the administration of drugs, rats were individually placed in a metabolic cage, and then the cumulative urine excreted was measured at the end of the fifth hour in all groups. The $\mathrm{pH}$ was directly determined on fresh urine sample using a $\mathrm{pH}$-meter. Also, the urinary electrolyte $\left(\mathrm{Na}^{+}, \mathrm{K}^{+}, \mathrm{Cl}-\right)$ concentrations were analyzed using a semiautomatic Biochemistry Analyzer (Beckman AutoMate; CX9 PRO., USA) and $\mathrm{Na}^{+} / \mathrm{K}^{+}$ratio was calculated to evaluate the natriuretic activity of different extracts.

\section{Statistical analysis}

In vitro results were expressed as mean \pm standard deviation (SD). The differences between extracts were determined by analysis of variance (one-way ANOVA) followed by Dunnett's test. The in vivo results were

Step 4: Also, the right femoral vein was cannulated for the intravenous injection of the plant extracts

Step 5: After a steady baseline, the blood pressure was obtained for at least $15 \mathrm{~min}$, methanol extract and ethyl acetate extract were injected intravenously in doses of 0.04 , $0.12,0.4,1.2,4$, and $12 \mathrm{mg} / \mathrm{kg}$

Step 6: Blood pressure was allowed to stabilize before any further administration of the extract

Step 7: The changes in diastolic blood pressure, systolic blood pressure and mean arterial blood pressure were recorded and expressed as percent of their respective control values obtained before the administration of test substances

\section{Notes}

1. Blood pressure can also be measured by tail-cuff method which is less accurate. But it does not require any surgery and can be repeated almost indefinitely

2. Inhalational anesthetic may be used instead of intraperitoneal injection

\section{References}

Abdalla et al., 1994 
presented as mean \pm standard error of mean (S.E.M) and were compared using Student's t-test. All results were analyzed using GraphPad Prism version 5.00. Differences were considered significant at $p<0.05$.

\section{Results}

\section{Identification of isolated compounds}

This phytochemical investigation revealed the isolation of two compounds (Figure 1), katuranin (1) and 5isopropyl-3-methylphenol (2) .

Katuranin (1): Tetra-hydroxylated flavanone; katuranin or aromadendrin which was isolated as white amor-

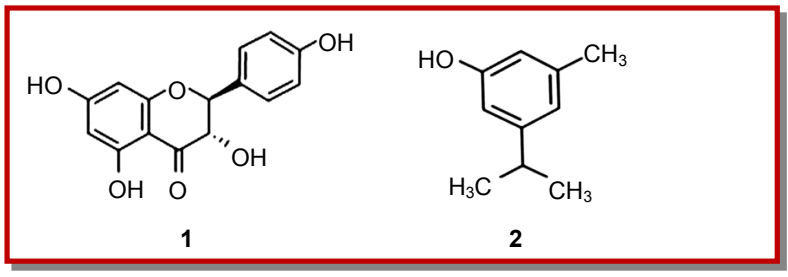

Figure 1: Structure of isolated compounds

phous powder after purification of fraction (5-6) by preparative thin layer chromatography using $20 \%$ methanol/chloroform. ${ }^{1} \mathrm{H}$ - and ${ }^{13} \mathrm{C}-\mathrm{NMR}$ spectroscopic data for katuranin was as follows: ${ }^{1} \mathrm{H}-\mathrm{NMR}(500 \mathrm{MHz}$,

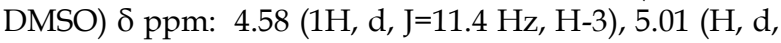
$\mathrm{J}=11.4 \mathrm{~Hz} \mathrm{H}-2), 5.90(1 \mathrm{H}, \mathrm{d}, \mathrm{J}=1.5 \mathrm{~Hz}, \mathrm{H}-8), 5,95(1 \mathrm{H}, \mathrm{d}$, $\mathrm{J}=1.5 \mathrm{~Hz}, \mathrm{H}-6), 6.79$ (2H, d, J=8.4 Hz, H-3' \& H-5'), 7.31 (2H, d, J=8.4 Hz, H-2' \& H-6'). ${ }^{13} \mathrm{C}-\mathrm{NMR}(500 \mathrm{MHz}$, DMSO) $\delta$ ppm: 71.9 (C-3), 83.3 (C-2), 95.5 (C-8), 96.5 (C6), 100.9 (C-10), 115.4 (C-3' \& C-5'), 128.0 (C-1'), 129.9 (C2' \& C-6'), 158.2 (C-9), 163.0 (C-4'), 163.7 (C-7), 167.4 (C5), $198.3(\mathrm{C}-4)$.

The mass spectrum of katuranin gave a molecular ion peak at $\mathrm{m} / \mathrm{z}=287.05611$, which correspond to the formula $[\mathrm{M}-\mathrm{H}]+$.

5-Isopropyl-3-methylphenol (2): Fraction (1-2) was purified by thin layer chromatography plates using $2 \%$ methanol/chloroform to give pure compound which

Table I

\begin{tabular}{|lcc|}
\hline \multicolumn{3}{|c|}{ Table I } \\
\hline \multicolumn{3}{|c|}{ Total polyphenols and flavonoids contents in } \\
O. glandulosum extracts \\
\hline Extracts & $\begin{array}{c}\text { Total phenolic con- } \\
\text { tent } \\
\text { (mg GAE/g DW) }\end{array}$ & $\begin{array}{c}\text { Total flavonoids } \\
\text { content } \\
\text { (mg Q E/g DW) }\end{array}$ \\
\hline Methanol & $179.9 \pm 0.8$ & $12.6 \pm 0.6$ \\
Chloroform & $239.9 \pm 1.5$ & $22.6 \pm 0.8$ \\
Ethyl acetate & $514.8 \pm 4.3$ & $8.5 \pm 0.2$ \\
Aqueous & $162.7 \pm 1.8$ & $6.2 \pm 0.6$ \\
Results are expressed as means $\pm \mathrm{SD}(\mathrm{n}=3)$ & \\
\hline
\end{tabular}

was identified as 5-isopropyl-3-methylphenol. ${ }^{1} \mathrm{H}$ - and 13C-NMR spectroscopic data of 5-isopropyl-3-methylphenol was as follows: ${ }^{1} \mathrm{H}-\mathrm{NMR}\left(500 \mathrm{MHz}, \mathrm{CDCl}_{3}\right) \delta$ ppm: 1.30 (6H, b.s, H-8 and H-9), 2.30 (3H, s, H-10), 3.40 (1H, b.s, H7), 6.63 (1H, m, H-6), 6.79 (1H, m, H-2), 7.11 $(1 \mathrm{H}, \mathrm{m}, \mathrm{H}-4) .{ }^{13} \mathrm{C}-\mathrm{NMR}\left(500 \mathrm{MHz}, \mathrm{CDCl}_{3}\right) \delta$ ppm: 16.0 (C-10), 18.0 (C-8 \& C-9), 22.0 (C-7), 109.7 (C-6), 116.9 (C2), 121.5 (C-4), 126.7 (C-3), 131.9 (C-5), 147.8 (C-2).

\section{Total polyphenols and flavonoids contents}

The total phenolics and flavonoids content among the different extracts of $O$. glandulosum are presented in Table I. The results showed that O. glandulosum fractions contained phenolic compounds in the following order: ethyl acetate extract> chloroform extract> methanol extract> aqueous extract, whereas the total flavonoids contents of plant extracts had the following order: chloroform extract $>$ methanol extract> ethyl acetate extract $>$ aqueous extract. As a result, the highest phenolic content was noticed in ethyl acetate extract with value of $514.8 \mathrm{mg}$ GAE/g of dry extract, whereas the highest total flavonoids content was recorded in chloroform extract $(22.6 \mathrm{mg} \mathrm{QE} / \mathrm{g}$ of dry extract)

\section{Anti-oxidant activity assessment}

\section{DPPH radical scavenging activity of extracts}

As seen in Figure 2A, ethyl acetate, methanol and chloroform extracts from the O. glandulosum leaves showed a stronger ability to scavenge DPPH radicals (2, 2-diphenyl-1-picryl-hydrazyl) than reference standard (butylated hydroxytoluene, $\mathrm{BHT}) ;\left(\mathrm{IC}_{50}=0.031 \pm 0.000\right.$ $\mathrm{mg} / \mathrm{mL})(\mathrm{p}<0.001)$ followed by $\mathrm{IC}_{50}$ values of $0.006 \pm$ $0.000 \mathrm{mg} / \mathrm{mL}, 0.017 \pm 0.000 \mathrm{mg} / \mathrm{mL}, 0.021 \pm 0.000 \mathrm{mg} /$ $\mathrm{mL}$, respectively. However, the aqueous extract showed the lowest scavenging activity with value of $\mathrm{IC}_{50}$ equal to $0.029 \pm 0.002 \mathrm{mg} / \mathrm{mL}$.

\section{Hydroxyl radical scavenging activity of extracts}

Similar to the DPPH radical scavenging activity results, all of the tested fractions of O. glandulosum were able to reduce the generation of hydroxyl radicals (Figure 2B) but the highest activity was found in ethyl acetate extract with $\mathrm{IC}_{50}$ values as follows: $0.285 \pm 0.008 \mathrm{mg} /$ $\mathrm{mL}, 0.642 \pm 0.000 \mathrm{mg} / \mathrm{mL}, 0.715 \pm 0.050 \mathrm{mg} / \mathrm{mL}$ and $0.936 \pm 0.010 \mathrm{mg} / \mathrm{mL}$ for ethyl acetate, chloroform, methanol, and aqueous extracts, respectively.

\section{Hypotensive effects of extracts in anesthetized rats}

Our results revealed that the intravenous administration of methanol and ethyl acetate extracts experimented at the range doses from 0.04 to $12 \mathrm{mg} / \mathrm{kg}$ body weight produced a dose-dependent and transitory hypotensive effect in the anesthetized rats by decreasing systolic, diastolic and mean blood pressure.

At the maximal injected dose $(1.2 \mathrm{mg} / \mathrm{kg})$ of the 


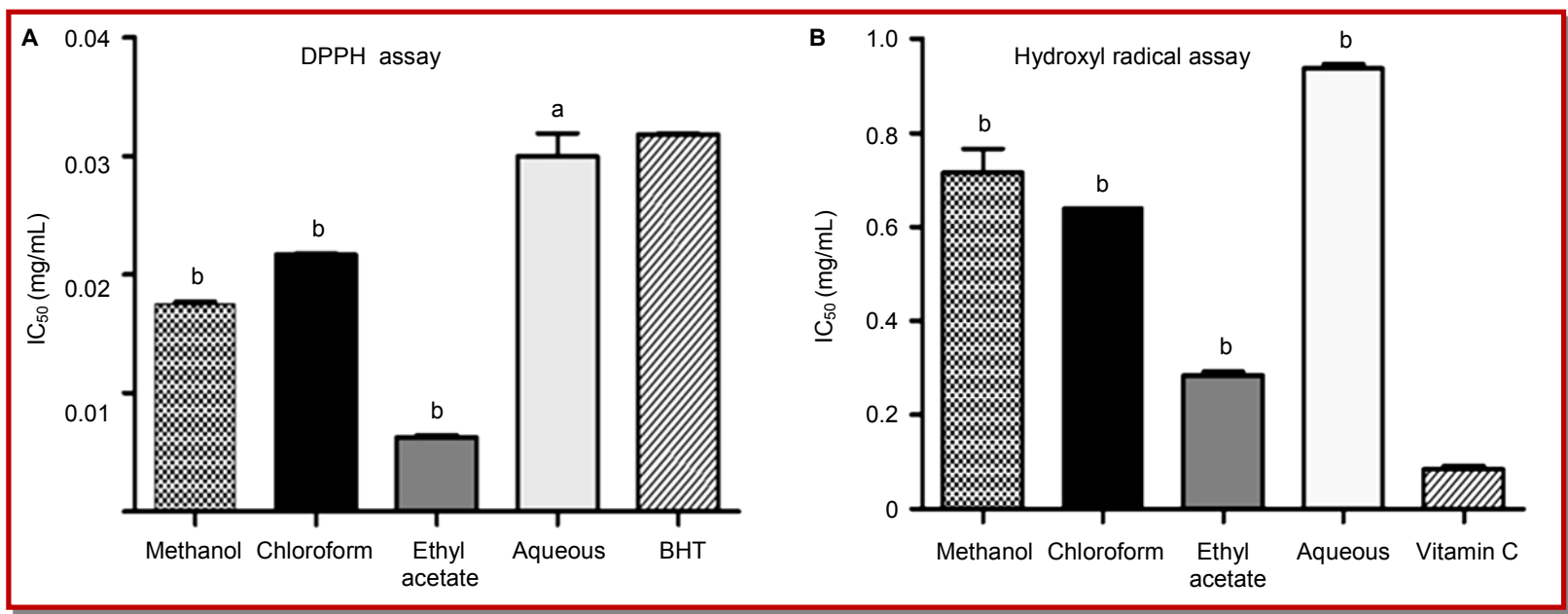

Figure 2: Free radical scavenging activity of different $O$. glandulosum extracts. Data were presented as $\mathrm{IC}_{50} \quad$ means $\pm \mathrm{SD}(\mathrm{n}=3)$; $\left(\mathrm{a} p<0.05,{ }^{b} \mathrm{p}<0.001\right)$ compared to butylated hydroxytoluene (BHT) and vitamin $\mathrm{C}$ as standards

Table II

Effects of methanol extract of $O$. glandulosum on urine output, $\mathrm{pH}$ and electrolytes excretion in rats

\begin{tabular}{|c|c|c|c|c|c|c|}
\hline Dose & $\begin{array}{l}\text { Volume } \\
\text { (mL/rat) }\end{array}$ & $\mathrm{pH}$ & $\mathrm{Na}^{+}(\mathrm{mmol} / \mathrm{L})$ & $\mathrm{K}^{+}(\mathrm{mmol} / \mathrm{L})$ & $\mathrm{Cl}^{-}(\mathrm{mmol} / \mathrm{L})$ & $\mathrm{Na}^{+} / \mathrm{K}^{+}$ \\
\hline Control $(5 \mathrm{~mL} / \mathrm{kg})$ & $2.7 \pm 0.3$ & $6.4 \pm 0.4$ & $64.8 \pm 5.5$ & $51.5 \pm 2.2$ & $66.2 \pm 4.6$ & $1.3 \pm 0.1$ \\
\hline Furosemide $(20 \mathrm{mg} / \mathrm{kg})$ & $10.7 \pm 0.9 c$ & $5.7 \pm 0.1$ & $116.6 \pm 12.1^{b}$ & $46.6 \pm 2.1$ & $645.4 \pm 94.4^{c}$ & $2.7 \pm 0.3^{b}$ \\
\hline Methanol extract $(100 \mathrm{mg} / \mathrm{kg})$ & $3.1 \pm 0.2$ & $6.2 \pm 0.3$ & $77.3 \pm 0.6$ & $58.2 \pm 4.3$ & $58.8 \pm 5.4$ & $1.4 \pm 0.1$ \\
\hline Methanol extract $(300 \mathrm{mg} / \mathrm{kg})$ & $3.7 \pm 0.4$ & $6.0 \pm 0.1$ & $84.4 \pm 1.5^{b}$ & $52.9 \pm 2.3$ & $80.8 \pm 7.5$ & $1.6 \pm 0.1$ \\
\hline Methanol extract $(600 \mathrm{mg} / \mathrm{kg})$ & $4.8 \pm 0.6^{a}$ & $6.4 \pm 0.2$ & $92.0 \pm 3.8^{b}$ & $35.5 \pm 2.2^{c}$ & $155.6 \pm 22.8^{b}$ & $2.6 \pm 0.2^{b}$ \\
\hline
\end{tabular}
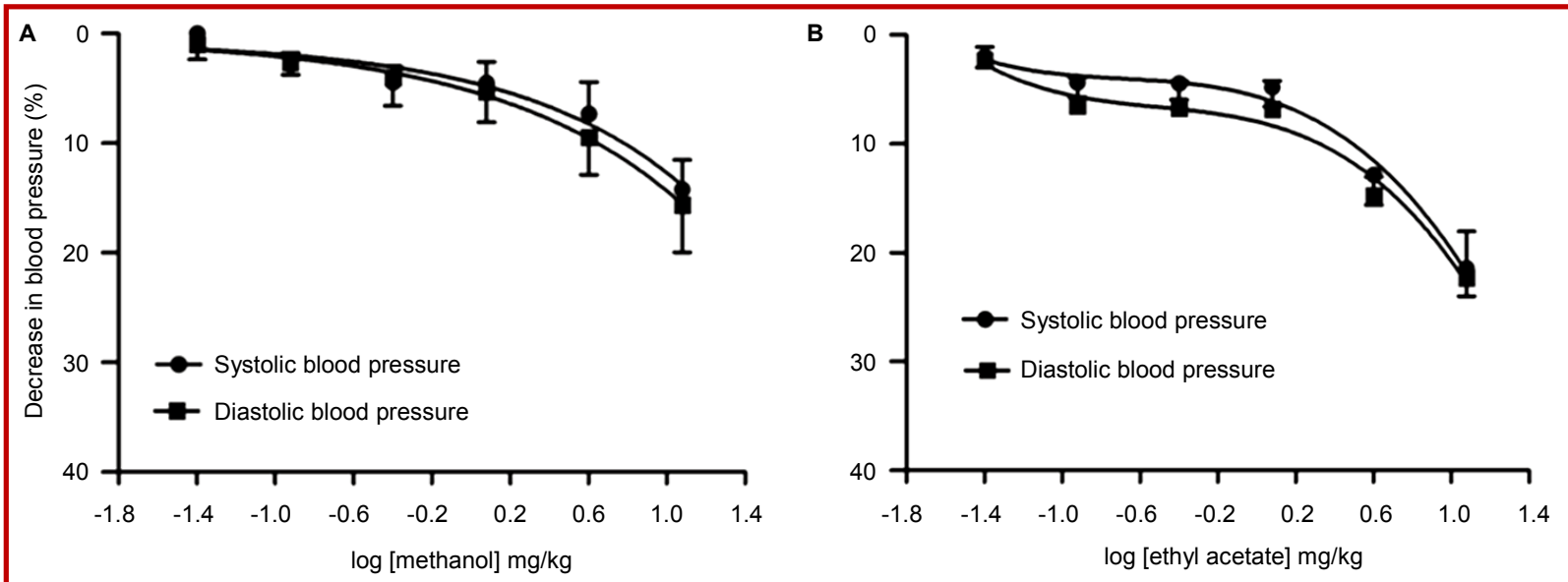

Figure 3: Concentration-response curves of methanol and ethyl acetate extract of O. glandulosum on systolic and diastolic blood pressure of anesthetized rats. Values are means $\pm \operatorname{SEM}(n=6)$

methanol extract, the average systolic blood pressure and diastolic blood pressure were decreased significantly by $(14.2 \pm 2.7 \% ; 15.7 \pm 4.3)$ (Figure 3$)$, whereas a percent decrease in systolic and diastolic blood pressure for ethyl acetate extract was about $(21.4 \pm 2.6 \% ; 22.3 \pm$ $4.3 \%$ ) (Figure 3). The hypotensive response at a dose of $12 \mathrm{mg} / \mathrm{kg}$ was found to be more potent with the ethyl acetate extract for which the maximal fall in mean arterial blood pressure was about $(22.0 \pm 3.1 \%)$ in comparison with the maximal fall observed with the methanol extract $(15.2 \pm 3.2 \%)$ (Figure 4$)$.

\section{Diuretic activity of plant extracts}

Effect of methanol extract on urinary output 


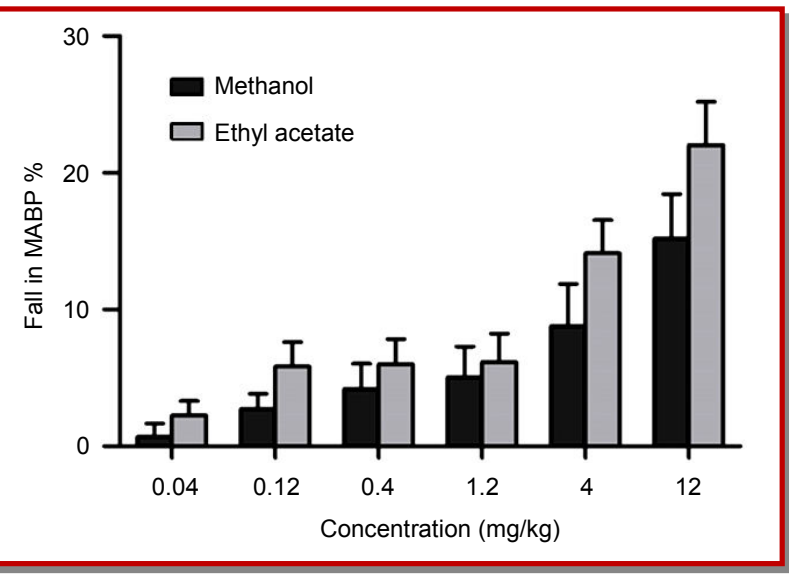

Figure 4: Dose-dependent hypotensive effect of methanol and ethyl acetate of $O$. glandulosum on mean arterial blood pressure $(\mathrm{MABP})$ in anaesthetized rats. Values shown are means \pm SEM $(n=6)$

The results demonstrated that methanol extract act as diuretic in a dose-dependent manner. Methanol extract at doses of 100 and $300 \mathrm{mg} / \mathrm{kg}$ increased slightly the urine volume $(16.0 \%$ and $37.5 \%$, respectively). However, the dose of $600 \mathrm{mg} / \mathrm{kg}$ contributed to potent urine excretion $(77.0 \%)$ with statistical significance $(p<0.05)$ when compared to control group (Table II). The reference diuretic, furosemide $(20 \mathrm{mg} / \mathrm{kg})$, significantly increased urine output by $297.0 \% \quad(p<0.001)$, when compared to the saline-treated group.

\section{Effect of methanol extract on urinary $\mathrm{pH}$}

Concerning the urinary $\mathrm{pH}$, weak acidification in urinary $\mathrm{pH}$ profile was observed after five hours following the administration of furosemide and the three doses of methanol extract of O. glandulosum (Table II), but they were too weak to reach statistical significance compared to control group which had $\mathrm{pH}$ value of 6.41.

\section{Effect of methanol extract on urinary electrolyte excre- tion}

Furosemide increased the sodium and chloride excretion $(80.0 \% ; \mathrm{p}<0.01$ and $847.9 \% ; \mathrm{p}<0.001$, respectively) in a dose-dependent manner but not that of potassium (Table II). Actually there was a small decrease in urinary concentration of potassium (-9.5\%) when compared to control group.

The sodium excretion was increased significantly ( $p$ $<0.01)$ by the two doses, 300 and $600 \mathrm{mg} / \mathrm{kg}(30.2 \%$ and $42.0 \%$, respectively), which was in agreement with the urine volume. However, $600 \mathrm{mg} / \mathrm{kg}$ dose of methanol extract produced highly significant decrease in potassium excretion $(31.0 \% ; \mathrm{p}<0.001)$ and strong increase in chloride $(135.0 \% ; \mathrm{p}<0.01)$ compared to the control group.

The ratio $\mathrm{Na}^{+} / \mathrm{K}^{+}$determines the natriuretic activity and value equal or greater than 2 indicates favorable natriuretic effect. Among all administered doses, 600 $\mathrm{mg} / \mathrm{kg}$ of methanol extract increased significantly $(\mathrm{p}<0.01)$ the $\mathrm{Na}^{+} / \mathrm{K}^{+}$ratio, which was similar to that of furosemide which had $\mathrm{Na}^{+} / \mathrm{K}^{+}$ratio of $2.7 \pm 0.3$.

\section{Discussion}

In this study, the hypotensive, diuretic activities of $O$. glandulosum extracts were investigated. The radical scavenging activity of $O$. glandulosum extracts against DPPH radical and hydroxyl radicals were also assessed. In addition, the phytochemical analysis of ethyl acetate extract was carried out. Phytochemical analysis of ethyl acetate extract from $O$. glandulosum revealed the isolation two compounds, katuranin, a flavanonol which was isolated previously from greek $O$. vulgare (Exarchou et al., 2003) and O. glandulosum by HPLC coupled to diode-array detection and APCI-MS (Skoula et al., 2008). The proposed structure of this flavanonol was confirmed by comparison of NMR data with those reported in the literature (Exarchou et al., 2003). The second compound was 5-isopropyl-3-methylphenol. To the best of our knowledge, this compound was isolated from the leaves of this species and the genus Origanum for the first time.

Phenolic compounds have a protective role against many diseases due to their structural properties, and biological effects including high antioxidant capacity in vitro and in vivo, anti-inflammatory and antihypertensive effects (Miranda et al., 2016).

Results obtained in the present study revealed that the level of these phenolic compounds in the various plant extracts was important and this could be due to different degree of polarity of the solvents used for the extraction of polyphenolic compounds where ethyl acetate was the best solvent for the extraction of phenolic compounds.

There are many anti-oxidant tests to evaluate the antioxidant capacity of natural plant extracts. It is imperative to use more than one anti-oxidant test when evaluate the anti-oxidant efficacy of plant extracts because different extract possess different phytochemicals in different concentrations that may act through different mechanisms.

In the present study, DPPH radical scavenging activity ranged from 0.006 to $0.029 \mathrm{mg} / \mathrm{ml}$ among the four plant fractions, with the highest scavenging capacity exhibited by ethyl acetate extract.

According to many reports, there is a highly positive relationship between polyphenols and flavonoids, and anti-oxidant activities in many plant species (Kim et al., 2012; Bouaziz et al., 2015). So, based on the obtained results, it is highly possible that the polyphenols and flavonoids contents may contribute to the observed anti -oxidant activity in DPPH free radical scavenging activity, as indicated by the good correlation coefficient 
$\left(\mathrm{R}^{2}=0.50\right)$. Furthermore, it is obvious that although the content of polyphenols of O. glandulosum in chloroform extract was significantly higher than in the methanol extract, their DPPH activity were close. This confirmed once again that the anti-oxidant capacity depends not only on the quantity, but also on the type of polyphenols and flavonoids present in the extracts. Thus, both the configuration and total number of hydroxyl groups substantially influence the mechanism of the anti-oxidant activity (Tuberoso et al., 2010; Fraga et al., 2010).

Hydroxyl free radicals have been implicated in the etiology of many pathologies and eventually resulted in the cell injury/death. Therefore, the scavenging of hydroxyl radicals by extracts may provide a significant protection to biomolecules against free radicals (Govindan and Muthukrishnan, 2013).

In this study, plant extracts displayed different potential in scavenging hydroxyl radical which is positively related to their amount of total phenolic and flavonoids contents $\left(\mathrm{R}^{2}=0.90\right)$ and this might be due to their active electron donor ability of hydroxyl substitution.

The leaves of $O$. glandulosum are commonly used in traditional Algerian medicine as antihypertensive therapy, but the pharmacological evidences of their activity are lacking. Therefore, the hypotensive effect of methanol extract and ethyl acetate extract from $O$. glandulosum leaves was reported for the first time. Our data reveal that ethyl acetate extract elicited a significant hypotensive response than methanol extract. These significant effects may be solidly related to their phenolic and flavonoids contents. Previous studies reported that these secondary metabolites as flavonoids are capable of exerting their antihypertensive effects by different pathways, such as endothelium dependent vasodilation involving $\mathrm{NO}$ production, reduction of intracellular $\mathrm{Ca}^{2+}$ (Nugroho et al., 2013) and angiotensin converting enzyme inhibition (AlarcónAlonso et al., 2012). In this study, the phytochemical screening analysis confirmed the presence of flavonoids as katuranin, thus, this bioactive principle, at least inpart, may be responsible for the observed hypotensive effect.

It is known that drugs with diuretic action such as loop diuretics and thiazides, either alone or in combination with other drugs are used for the treatment of various disorders such as hypertension, nephritis, chronic renal failure, eclampsia and heart failure, especially by increasing urine flow and renal sodium excretion (Ribeiro et al., 2015). Despite their high efficiency, many diuretics have been associated with undesirable side effects, including electrolyte imbalance, metabolic alkalosis, hyperuricemia, development of new-onset diabetes metabolic alterations, and activation of the renin-angiotensin-neuroendocrine systems (Kateel et al., 2014; Ribeiro et al., 2015). Hence, there is a need for new diuretics with lower potential for adverse effects, such as the plant-based substances which are considered to be relatively safe. In addition, many plants used for the treatment of hypertension in different systems of traditional medicine have shown diuretic activity when tested on animal models (Jabeen and Aslam 2013; de AF Da et al., 2015).

In the present study, the diuretic effect of orally administered methanol extract of $O$. glandulosum was evaluated in normal rats after single oral dose for five hours. As result, methanol extract produced diuresis and sodium and chloride excretion in rats after a single dose for five hours when compared to furosemide (20 $\mathrm{mg} / \mathrm{kg}$ ), but the mechanism through which methanol extract of $O$. glandulosum exerts its diuretic effect still unclear knowing that this is the first report of diuretic activity of $O$. glandulosum leaves extract.

Previous studies demonstrated that several secondary metabolites of plants could be responsible for the diuretic effects, such as flavonoids, alkaloids, tannins, saponins, terpenoids or organic acids (Jabeen and Aslam, 2013). Several isoflavonoids have been reported to cause inhibition of the $\mathrm{Na}^{+}-\mathrm{K}^{+}-2 \mathrm{Cl}-$ co-transporter, an increase in diuresis, natriuresis, glomerular filtration and and $\mathrm{Na}^{+}$and $\mathrm{K}^{+}$excretion (Montejano-Rodri'guez et al., 2013). Thus, phenolic and flavonoids compounds evaluated in $O$. glandulosum may be considered as responsible for this diuretic effect because of its high phenolic content. As results, all evidences in this work corroborate the ethnopharmacological application of $O$. glandulosum as hypotensive agent where increased diuresis is desired and may lay the foundation for the use of this plant in folk medicine.

\section{Conclusion}

O. glandulosum leaf extracts exhibited strong antioxidant activities and this may be related to their phenolics contents. The extracts are able to reduce the blood pressure and to enhance the urine output and the electrolytes excretion of sodium and chloride and this finding may explain the blood pressure lowering effect of this plant.

\section{Ethical Issue}

The ethical issue, care and handling of animals followed the internationally accepted procedures according to the Institute for Laboratory Animal Research's Guide for the Care and Use of Laboratory Animals.

\section{Conflict of Interest}

The authors had no conflict of interest associated with this work. 


\section{Acknowledgements}

This work was supported by the Algerian Ministry of Higher Education and Scientific Research and the Thematic Agency for Research in Health Sciences. We express our gratitude to these organizations.

\section{References}

Abdalla S, Abu Zarga M, Sabri S. Effects of the flavone luteolin, isolated from Colchicum ritchii, on guinea-pig isolated smooth muscle and heart and on blood pressure and blood flow. Phytother Res. 1994; 8: 265-70.

Alarcón-Alonso J, Zamilpa A, Alarcón Aguilar F, Herrera-Ruiz M, Tortoriello J, Jimenez-Ferrer E. Pharmacological characterization of the diuretic effect of Hibiscus sabdariffa Linn (Malvaceae) extract. J Ethnopharmacol. 2012; 139: 751-56.

Athiroh N, Permatasari N, Sargowo D, Widodo MA. Antioxidative and blood pressure lowering effects of Scurrula atropurpurea on deoxycorticosterone acetate-salt hypertensive rats. Biomarkers Genomic Med. 2014; 6: 32-36.

Bahorun T, Gressier B, Trotin F, Brunet C, Dine T, Luyckx M, Vasseur J, Cazin M, Cazin JC, Pinkas M. Oxygen species scavenging activity of phenolic extracts from hawthorn fresh plant organs and pharmaceutical preparations. Arzneimittel-Forschung 1996; 46: 1086-89.

Belhattab R, Larous L, Figueiredo AC, Santos PAG, Barroso J G, Pedro LG. Origanum glandulosum Desf. grown wild in Algeria: Essential oil composition and glycosidic bound volatiles. Flav Fragr J. 2005; 20: 209-12.

Bouaziz A, Khennouf S, Abu zarga M, Abdalla S, Baghiani A, Charef N. Phytochemical analysis, hypotensive effect and antioxidant properties of Myrtus communis L. growing in Algeria. Asian Pac J Trop Biomed. 2015; 5: 19-28.

Boudjelal A, Henchiri C, Sari M, Sarri D, Hendel N, Benkhaled A, Ruberto G. Herbalists and wild medicinal plants in M'Sila (North Algeria): An ethnopharmacology survey. J Ethnopharmacol. 2013; 148: 395-402.

Burits M, Bucar F. Antioxidant activity of Nigella sativa essential oil. Phytother Res. 2000; 14: 323-28.

Chouhan HS, Singh SK. Phytochemical analysis, antioxidant and anti-inflammatory activities of Phyllanthus simplex. J Ethnopharmacol. 2011; 137: 1337-44.

de AF Da RD, de Souza P, Crestani S, Júnior AG, Boligon AA, Athayde ML, da Silva-Santos JE. Hypotensive and diuretic effect of the butanolic soluble fraction of the hydroethanolic extract of bark of Scutia buxifolia Reissek in rats. J Ethnopharmacol. 2015; 172: 395-401.

Exarchou V, Godejohann M, Van Beek T, Gerothanassis P, Vervoort J. LC-UV-Solidphase extraction-NMR-MS combined with a cryogenic flow probe and its application to the identification of compounds present in Greek oregano. Anal Chem. 2003; 75: 6288-94.

Fraga CG, Galleano M, Verstraeten SV, Oteiza PI. Basic biochemical mechanisms behind the health benefits of polyphenols. Mol Aspects Med. 2010; 31: 435-45.
Gönenç A, Hacısevki A, Tavil Y, Çengel A, Torun M. Oxidative stress in patients with essential hypertension: A comparison of dippers and non-dippers. Eur J Int Med. 2013; 24: 139-44.

Govindan P, Muthukrishnan S. Evaluation of total phenolic content and free radical scavenging activity of Boerhavia erecta. J Acute Med. 2013; 3: 103-09.

Gutiérreza YP, Gutiérreza AP, Leónb AR, Garcíaa KC. Role of oxidative stress in the pathogenesis of hypertension. Cor Salud. 2014; 6: 181-92.

Jabeen Q, Aslam N. Hypotensive, angiotensin converting enzyme (ACE) inhibitor and diuretic activities of the aqueous-methanol extract of Ipomoea reniformis. Iran J Pharm Res. 2013; 12: 769-76.

Kateel R, Rai MS, Ashok Kumar J. Evaluation of diuretic activity of gallic acid in normal rats. J Sci Innov Res. 2014; 3: 217-20.

Khadir A, Bendahou M, Benbelaïd F, Ghellaï L, Abdoune MA, Bellahsene C, Zenati F, Abdelouahid D, Muselli A, Paollini J, Desjobert JM, Costa J. Efficacy of the essential oil of Origanum glandulosum Desf against skin infections with PVL -producing Staphylococcus aureus strains in mice. African J Microbiol Res. 2013; 7: 2656-61.

Kim YS, Lee SJ, Hwang JW, Kim UK, Kim SE, Kim EH, Moon $\mathrm{SH}$, Jeon BT, Park JP. In vitro protective effects of Thymus quinquecostatus Celak extracts on t-BHP-induced cell damage through antioxidant activity. Food Chem Toxicol. 2012; 50: 4191-98.

Li HB, Cheng KW, Wong CC, Fan KW, Chen F, Jiang Y. Evaluation of antioxidant capacity and total phenolic content of different fractions of selected microalgae. Food Chem. 2007; 102: 771-76.

Li YH, Jiang B, Zhang T, Mu WM, Liu J. Antioxidant and free radical scavenging activities of chickpea protein hydrolysate (CPH). Food Chem. 2008; 106: 444-50.

Markham KR. Techniques of flavonoid identification. London, Academic Press, 1982, p 113.

Miranda AM, Steluti J, Fisberg RM, Marchioni DM. Association between polyphenol intake and hypertension in adults and older adults: A population-based study in Brazil. PLoS One. 2016; 11: $\mathrm{e} 0165791$.

Montejano-Rodríguez JR, Almaguer-Vargas G, Gayosso-DeLucio JA, Ocharan Herna'ndez M E, Moreno Martı́nez RE, Herna'ndez Caballero M E, Torres-Valencia JJM, Sierra Ramı'rez JA. Evaluation of the diuretic activity of the ethanolic extract of Geranium seemannii Peyr. in Wistar rats. J Pharm Res.2013; 6: 709-13.

Nugroho AE, Malik A, Pramono S. Total phenolic and flavonoid contents, and in vitro antihypertension activity of purified extract of Indonesian cashew leaves (Anacardium occidentale L.). Int Food Res J. 2013; 20: 299-305.

Oukil N, Bedjou F, Maiza-Benabdesselam F, Chibane M. Antioxidant activity and separation of phenolic compounds of Origanum glandulosum from north Algeria by high performance liquid chromatography (HPLC). African J Biotechnol. 2011; 10: 3451-54.

Qu Z, Zhang J, Gao W, Chen H, Huang H, Huo L, Lia H. 
Antihypertensive and cardioprotective effects of cerebral care granule ${ }^{\circledR}$ on spontaneously hypertensive rats from the perspective of the gaseous triumvirate $\mathrm{NO}-\mathrm{CO}-\mathrm{H} 2 \mathrm{~S}$ system. Environ Toxicol Pharmacol. 2016; 41: 22-31.

Ribeiro EF, Reis CF, Carvalho FS, Abreu JPS, Arruda AF, Garrote CFD, Rocha ML. Diuretic effects and urinary electrolyte excretion induced by Aspidosperma subincanum Mart. and the involvement of prostaglandins in such effects. J Ethnopharmacol. 2015; 163: 142-48.

Skoula M, Grayer RJ, Kite GC, Veitch NC. Exudate flavones and flavanones in Origanum species and their interspecific variation. Biochem Syst Ecol. 2008; 36: 646-54.

Tuberoso CIG, Rosa A, Bifulco E, Melis MP, Atzeri A, Pirisi F M, Dessì MA. Chemical composition and antioxidant activities of Myrtus communis L. berries extracts. Food Chem. 2010; 123: 1242-50.

Wu P, Ma G, Li N, Deng Q, Yin, Huang R. Investigation of in vitro and in vivo antioxidant activities of flavonoids rich extract from the berries of Rhodomyrtus tomentosa (Ait.) Hassk. Food Chem. 2015; 173: 194-202.

Yadegarinia D, Gachkar L, Rezaei MB, Taghizadeh M, Astaneh SA, Rasooli I. Biochemical activities of Iranian Mentha piperita L. and Myrtus communis L. essential oils. Phytochemistry 2006; 67: 1249-55.

Zhang G, Zeng X, Han L, Wei J, Huang H. Diuretic activity and kidney medulla AQP1, AQP2, AQP3, V2R expression of the aqueous extract of sclerotia of Polyporus umbellatus FRIES in normal rats. J Ethnopharmacol. 2010; 128: 433-37. 